\title{
Fósforo e potássio na sucessão trigo/milho: épocas e formas de aplicação
}

\author{
Phosphorus and potassium in wheat/corn succession: season and \\ methods of application
}

Paulo Sérgio Pavinato $^{1}$ Carlos Alberto Ceretta ${ }^{2}$

\section{RESUMO}

Com a difusão do plantio direto e melhoria na fertilidade dos solos no Sul do Brasil, passou-se a cogitar mais intensamente a distribuição nas culturas no inverno dos fertilizantes fosfatados e potássicos das culturas em sucessão no verão. Com isso, o produtor teria maior agilidade à implantação das culturas no verão, melhor utilização de maquinário e mãode-obra, além de menor custo dos fertilizantes e do seu transporte. O trabalho teve por objetivo avaliar a possibilidade de distribuir na cultura no inverno, o fósforo e potássio que seriam aplicados na cultura em sucessão no verão. $O$ experimento foi realizado em 2002 e 2003, na Fazenda Paineira da SLC Agrícola Ltda em Coronel Bicaco, RS, em um Latossolo Vermelho Distroférrico típico com teores muito altos de fósforo e potássio. Os tratamentos constituíram-se da aplicação na cultura no inverno do fertilizante recomendado para a cultura no verão em sucessão, distribuído na linha de semeadura ou a lanço. $O$ delineamento foi de blocos ao acaso e com três repetições dos nove tratamentos. Foi evidenciada a baixa probabilidade de resposta em produtividade de grãos à adubação com fósforo $e$ potássio em solo com altos teores destes nutrientes, mostrando que, nestas condições, a aplicação na cultura no inverno da adubação que seria utilizada na cultura no verão em sucessão, pode ser justificada pelas facilidades operacionais da adubação em sistemas.

Palavras-chave: manejo de fertilizantes, sucessão de culturas, adubação.

\section{ABSTRACT}

The increase in adoption of no till management practiced in Southern Brazil is leading farmers to wonder about the advantages of fertilizer application in winter crops to be fed by the subsequent summer crop. Such practice would potentially result in a more flexible seeding schedule and a more efficient use of machinery, work force and fertilizers. This work had the objective of evaluating the anticipation of the phosphorus and potassium application from summer to winter. The experiment was made in 2002 and 2003, in SLC Agrícola Ltda at Fazenda Paineira in Coronel Bicaco, RS, in a Hapludox with high levels of phosphorus and potassium. The treatments were composed of the application in the winter crop of the recommended fertilizers for the next summer crop, in the seed line or broadcast distribution. The experiment was arranged in a randomized block design with three blocks and nine treatments. A low response was noticed in grain yield with the phosphorus and potassium application in soil with high levels of these nutrients, indicating that in these conditions the application of recommended fertilizers for summer crop in the winter crop, can be justified by the operation facilities in the system application of fertilizers.

Key words: fertilizers management, crops succession, fertilization.

\section{INTRODUÇÃO}

O plantio direto, embora tenha sido introduzido na década de 1970, teve grande expansão no Rio Grande do Sul e no Brasil, somente na primeira metade da década de 90 , proporcionando diminuição acentuada na erosão, favorecendo assim a construção da fertilidade dos solos. Alta disponibilidade de nutrientes, principalmente fósforo e potássio, podem ocorre em camadas mais superficiais do solo sob plantio direto. Isso ocorre principalmente pela aplicação dos fertilizantes em superfície ou em pequenas profundidades, do calcário em superfície, da ausência de revolvimento do solo, da manutenção e ciclagem de nutrientes através de resíduos culturais e das menores perdas de nutrientes por erosão.

$\mathrm{O}$ ambiente proporcionado no solo pelo plantio direto tem permitido que técnicos e

${ }^{1}$ Parte da dissertação do primeiro autor apresentada no Programa de Pós-graduação em Ciência do Solo da Universidade Federal de Santa Maria (UFSM), Santa Maria, RS.

${ }^{2}$ Engenheiro agrônomo, MSc, em Ciência do Solo, UFSM. E-mail: pspavinato@fca.unesp.br

${ }^{3}$ Engenheiro agrônomo, Doutor, Professor titular do Departamento de Solos da UFSM, 97105-900, Santa Maria, RS. E-mail: ceretta@ccr.ufsm.br. Bolsista do Conselho Nacional de Desenvolvimento Científico e Tecnológico. Autor para correspondência. 
produtores apliquem na cultura no inverno parte ou todo o fertilizante que seria utilizado nas culturas comerciais no verão. Esta técnica está se expandindo entre produtores como forma de dar maior agilidade nas práticas de lavoura e melhorar a utilização de mão-de-obra e máquinas em períodos mais ociosos, em detrimento dos períodos de estrangulamento, resultando em maior agilidade na implantação das culturas no verão. Com isso, culturas importantes como milho e soja, poderiam ser semeadas sem o uso de fertilizantes fosfatados e potássicos, podendo também reduzir custos na aquisição dos fertilizantes, bem como no seu transporte. Contudo, deve-se considerar também as características das culturas, pois existem espécies mais exigentes em fósforo (PÖTTKER, 1999). Evidentemente, no caso de gramíneas, a opção seria lançar mão de fontes de fertilizantes e aplicar menores quantidades, já que há necessidade da aplicação de nitrogênio na semeadura.

Considerando-se que a difusão é o principal processo de movimentação do fósforo e potássio às raízes, deve-se considerar que um dos requisitos básicos para que a prática de distribuir antecipadamente no inverno a adubação das culturas, no verão, é que o solo apresente teores de fósforo e potássio acima do nível crítico, também denominado nível de suficiência, a partir do qual são aplicados nutrientes em quantidades suficientes para repor a exportação pelas culturas. Isso porque nestas condições, a probabilidade de resposta das culturas à aplicação de fertilizantes é baixa (HECKMANN, 2003), o que justificaria a afirmação de que as distribuições dos fertilizantes a lanço em superfície ou incorporado na linha de semeadura podem não afetar a produtividade das culturas. Introduzir esta prática em solos com níveis de $\mathrm{P}$ e $\mathrm{K}$ abaixo do nível crítico é possibilitar a diminuição na produtividade da cultura no verão, motivo pelo qual deve ser evitada.

A hipótese do trabalho é de que, na sucessão trigo/milho, a produtividade de grãos de milho independe das épocas e formas de aplicação do fósforo e potássio, quando estes estiverem acima do nível crítico no solo. $\mathrm{O}$ objetivo foi avaliar a possibilidade de distribuir na cultura, no inverno, o fósforo e potássio que seria aplicado na cultura em sucessão no verão.

\section{MATERIAL E MÉTODOS}

O experimento foi conduzido em área da Fazenda Paineira, da SLC Agrícola Ltda, em Coronel Bicaco, RS, localizada na região fisiográfica do Vale do Uruguai, no período de junho de 2002 a abril de 2003. O solo pertence à unidade de mapeamento Santo Ângelo, classificado como
Latossolo Vermelho Distroférrico típico, o qual se caracteriza por ser profundo, avermelhado, textura argilosa com presença de óxidos. A área onde foi conduzido o experimento era utilizada com rotações de culturas e estava sob plantio direto há 8 anos. O delineamento experimental utilizado foi de blocos ao acaso com três repetições e parcelas de 10 x 50m.

O solo apresentava as seguintes características na profundidade de $0-10 \mathrm{~cm}$ no momento da implantação do experimento: $\mathrm{pH}-\mathrm{H}_{2} \mathrm{O} 5,9 ; 43 \mathrm{~g} \mathrm{~kg}^{-1}$ de $\mathrm{MO} ; 15,0 \mathrm{e}$ acima de $200 \mathrm{mg} \mathrm{dm}^{-3}$ de $\mathrm{P}$ e $\mathrm{K}$, respectivamente; 0,1 , 6,7 e $2,8 \mathrm{cmol}_{\mathrm{c}} \mathrm{dm}^{-3} \mathrm{de} \mathrm{Al}, \mathrm{Ca}$ e $\mathrm{Mg}$, respectivamente, e saturação por bases de $75 \%$. Na profundidade de 10 20cm: $\mathrm{pH}-\mathrm{H}_{2} \mathrm{O} 5,5 ; 34 \mathrm{~g} \mathrm{~kg}^{-1}$ de MO; 8,0 e $148 \mathrm{mg} \mathrm{dm}^{-3}$ de P e K, respectivamente; $0,1,5,7$ e $2,5 \mathrm{cmol}_{\mathrm{c}} \mathrm{dm}^{-3} \mathrm{de}$ $\mathrm{Al}, \mathrm{Ca}$ e $\mathrm{Mg}$, respectivamente, e saturação por bases de $69 \%$. De acordo com estes dados, os teores de fósforo e potássio até $20 \mathrm{~cm}$ de profundidade são considerados muito altos (Comissão de Fertilidade do Solo RS/SC, 1994), portanto, a recomendação, neste caso, é aplicar somente a reposição das quantidades exportadas pelas culturas.

Foi estabelecida uma sucessão de culturas com trigo no inverno e milho no verão, cujos tratamentos foram os seguintes: testemunha sem aplicação de fósforo e potássio; $100 \%$ da adubação do trigo em linha (TLi) no inverno $+100 \%$ da adubação do milho em linha (MLi) no verão; $100 \%$ da adubação do TLi $+100 \%$ da adubação do milho a lanço (MLa), tudo no inverno; $100 \%$ da adubação do TLi + $100 \%$ da adubação do MLi, tudo no inverno; $100 \%$ da adubação do TLi $+40 \%$ da adubação do MLi no inverno e $+60 \%$ da adubação do MLi no verão; $100 \%$ da adubação do trigo a lanço (TLa) $+100 \%$ da adubação do MLa, tudo no inverno; $100 \%$ da adubação do TLa $+40 \%$ da adubação do MLa no inverno e $+60 \%$ da adubação do MLi no verão; $100 \%$ da adubação do TLa no inverno $+100 \%$ da adubação do MLa no verão; $100 \%$ da adubação do TLa no inverno + $100 \%$ da adubação do MLi no verão.

As quantidades de fertilizantes para o trigo foram de $30 \mathrm{~kg} \mathrm{ha}^{-1}$ de $\mathrm{P}_{2} \mathrm{O}_{5}$ e $35 \mathrm{~kg} \mathrm{ha}^{-1}$ de $\mathrm{K}_{2} \mathrm{O}$, visando produzir até $2,0 \mathrm{Mg} \mathrm{ha}^{-1}$, enquanto que, para o milho, foram $40 \mathrm{~kg} \mathrm{ha}^{-1}$ de $\mathrm{P}_{2} \mathrm{O}_{5}$ e $60 \mathrm{~kg} \mathrm{ha}^{-1}$ de $\mathrm{K}_{2} \mathrm{O}$, visando produzir de 3,0 a 6,0Mg ha-1 de grãos (Comissão de Fertilidade do Solo RS/SC, 1995). A adubação nitrogenada foi uniforme para cada cultura, sendo de $60 \mathrm{~kg} \mathrm{ha}^{-1}$ de $\mathrm{N}$ para o trigo, dos quais $22 \mathrm{~kg} \mathrm{ha}^{-1}$ na semeadura e o restante em cobertura 33 dias após. Para o milho, foram $100 \mathrm{~kg} \mathrm{ha}^{-1}$ de $\mathrm{N}$, sendo $30 \mathrm{~kg} \mathrm{ha}^{-1}$ na semeadura e o restante em cobertura 43 dias após.

O trigo foi semeado em 20 de junho de 2002 com população de aproximadamente $400 \mathrm{mil}$ plantas ha ${ }^{-1}$ e espaçamento entre linhas de $17 \mathrm{~cm}$ e o milho 
foi semeado em 13 de novembro de 2002 com 62.500 plantas ha ${ }^{-1}$ e espaçamento entre linhas de $80 \mathrm{~cm}$. A cultivar de trigo foi a BRS 179 da Embrapa e o híbrido de milho foi o $30 \mathrm{~F} 44$ da Pioneer.

Foram determinados os teores de fósforo e potássio disponíveis no solo na instalação do experimento nas profundidades de 0-10 e 10-20cm e, após a colheita do milho, nas profundidades de 0-5, 5-10 e 10-20cm (TEDESCO et al., 1995). As produções de matéria seca do trigo e milho foram determinadas via coleta da parte aérea das plantas no pleno florescimento. No trigo, a amostra foi coletada em uma área de $0,75 \mathrm{~m}^{2}$ por parcela, a partir de três sub amostras de $0,5 \times 0,5 \mathrm{~m}$, enquanto que, no milho, as amostras foram de cinco plantas coletadas aleatoriamente na área útil de cada parcela. As amostras foram secas em estufa a $65^{\circ} \mathrm{C}$ até peso constante e moídas, inicialmente em triturador de forrageiras, e após em moinho Willey (<40 mesh). O fósforo e potássio acumulados no tecido vegetal foram determinados a partir da matéria seca (TEDESCO et al., 1995).

A produtividade de grãos do trigo foi determinada em uma área de $235 \mathrm{~m}^{2}$, que correspondeu a uma passada da colheitadeira com plataforma de $4,70 \mathrm{~m}$ de largura ao longo dos $50 \mathrm{~m}$ de comprimento da parcela, colhendo uma faixa central. A colheita do milho foi realizada manualmente, sendo colhidas 4 fileiras de $10 \mathrm{~m}$ de comprimento escolhidas aleatoriamente nas parcelas. As produtividades de grãos de trigo e milho foram corrigidas para zero de impurezas e $13 \%$ de umidade. Utilizou-se análise de variância e as médias foram comparadas pelo teste de Duncan a 5\% de probabilidade de erro.

\section{RESULTADOS E DISCUSSÃO}

Os teores de fósforo disponível no solo não foram alterados pela aplicação de fertilizantes fosfatados e potássicos, os quais se mantiveram nas faixas de 14,5 a $17,5 \mathrm{mg} \mathrm{dm}^{-3}$ na camada de $0-5 \mathrm{~cm}, 10,1$ a $15,2 \mathrm{mg}$ $\mathrm{dm}^{-3}$ para a camada de $5-10 \mathrm{~cm}$ e 4,9 a $7,9 \mathrm{mg} \mathrm{dm}^{-3}$ para a camada de $10-20 \mathrm{~cm}$. Isto mostra que o solo possui uma quantidade de fósforo na forma lábil, capaz de ser liberado à solução do solo, mantendo um tamponamento no nível disponível na solução, o que é justificado pela não alteração na testemunha após os dois cultivos, quando comparado com o original do solo.

Os teores de potássio disponível no solo também não foram alterados com o uso de fertilizantes potássicos, mesmo porque seus teores até $20 \mathrm{~cm}$ de profundidade já estavam muitos altos quando da instalação do experimento. Com isso, torna-se pouco provável a possibilidade de detectar diferenças após apenas um ciclo da sucessão trigo/milho, mesmo porque sendo sob plantio direto é maior a possibilidade de manter o potássio no solo. Isso justifica porque em condições de solo semelhantes, o uso de potássio promoveu apenas $6 \%$ de acréscimo na produtividade de milho sob irrigação (SILVEIRA, 2002).

As produções de matéria seca na parte aérea do trigo e milho não foram influenciadas pela aplicação do fósforo e potássio e as quantidades acumuladas pelas duas culturas variaram de 15.957 a $17.409 \mathrm{~kg} \mathrm{ha}^{-1}$ evidenciando o alto potencial produtivo neste solo (Tabela 1). Contudo, houve uma tendência de menor produção de matéria seca, para ambas as culturas,

Tabela 1 - Produção de matéria seca da parte aérea do trigo, milho e quantidade acumulada pelas duas culturas, em função de épocas e formas de aplicação de fósforo e potássio.

\begin{tabular}{|c|c|c|c|c|}
\hline \multicolumn{2}{|c|}{ Aplicação de $\mathrm{P}_{2} \mathrm{O}_{5}$ e $\mathrm{K}_{2} \mathrm{O}$} & \multicolumn{3}{|c|}{ Produção de matéria seca } \\
\hline Trigo - Inverno & Milho - Verão & Trigo & Milho & Acumulada \\
\hline \multirow{2}{*}{\multicolumn{2}{|c|}{ Testemunha }} & \multicolumn{3}{|c|}{ 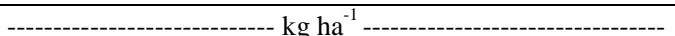 } \\
\hline & & $6.275^{\mathrm{ns}}$ & $10.000^{\mathrm{ns}}$ & $16.275 \mathrm{ab}^{* *}$ \\
\hline $100 \% \mathrm{TLi}^{*}$ & $100 \% \mathrm{MLi}$ & 6.484 & 10.925 & $17.409 \mathrm{a}$ \\
\hline $100 \% \mathrm{TLi}+100 \% \mathrm{MLa}$ & & 6.388 & 10.421 & $16.809 \mathrm{ab}$ \\
\hline $100 \% \mathrm{TLi}+100 \% \mathrm{MLi}$ & & 6.187 & 10.600 & $16.787 \mathrm{ab}$ \\
\hline $100 \% \mathrm{TLi}+40 \% \mathrm{MLi}$ & $60 \% \mathrm{MLi}$ & 6.353 & 10.592 & $16.945 \mathrm{ab}$ \\
\hline $100 \% \mathrm{TLa}+100 \% \mathrm{MLa}$ & & 5.786 & 10.171 & $15.957 \mathrm{~b}$ \\
\hline $100 \% \mathrm{TLa}+40 \% \mathrm{MLa}$ & $60 \% \mathrm{MLi}$ & 6.292 & 10.696 & $16.988 \mathrm{ab}$ \\
\hline $100 \% \mathrm{TLa}$ & $100 \% \mathrm{MLa}$ & 6.275 & 10.300 & $16.575 \mathrm{ab}$ \\
\hline $100 \% \mathrm{TLa}$ & $100 \% \mathrm{MLi}$ & 6.022 & 10.531 & $16.553 \mathrm{ab}$ \\
\hline $\mathrm{CV}(\%)$ & & 6,03 & 7,26 & 3,80 \\
\hline
\end{tabular}

* TLi = Adubação recomendada para o trigo aplicada na linha de semeadura. TLa = Adubação recomendada para o trigo aplicada a lanço na semeadura. $\mathrm{MLi}$ = Adubação recomendada para o milho aplicada na linha de semeadura. MLa = Adubação recomendada para o milho aplicada a lanço na semeadura.

** Médias não seguidas de mesma letra na coluna diferem pelo teste Duncan a 5\% de probabilidade de erro.

${ }^{\text {ns }}$ Não significativo. 
quando toda a adubação do trigo e do milho foi aplicada no trigo e a lanço $(100 \% \mathrm{TLa}+100 \% \mathrm{MLa}$, tudo no inverno), o que acabou se refletindo na menor produção de matéria seca acumulada pelas duas culturas, em comparação com a adubação feita tradicionalmente, ou seja, adubação na linha para cada cultura no momento da semeadura (100\% TLi no inverno $+100 \%$ MLi no verão).

No crescimento das culturas, o processo de difusão é a principal forma de movimentação de fósforo e potássio às raízes, sendo diretamente dependente da umidade do solo. Esta pode ser uma justificativa à alta produção de matéria seca do milho, pois durante seu ciclo a quantidade e distribuição das chuvas foram muito favoráveis ao crescimento de plantas. Esta justificativa também foi dada por HECKMANN \& KAMPRATH (1992) quando observaram que, em solo com muito alto teor de fósforo e alto teor de potássio disponível, o acúmulo de matéria seca de milho foi incrementado com a aplicação de até $56 \mathrm{~kg} \mathrm{ha}^{-1}$ de $\mathrm{K}_{2} \mathrm{O}$, não influenciando a forma de aplicação, se a lanço, em linha ou parte a lanço e parte em linha. A confirmação disso aconteceu quando os mesmos autores mostraram que, em ano com deficiência hídrica houve melhor desempenho nos tratamentos com a aplicação de, pelo menos, parte do potássio na linha de semeadura, em relação à aplicação a lanço, sendo que o fósforo, neste caso, foi sempre aplicado na linha de semeadura.

$\mathrm{O}$ acúmulo de fósforo no tecido do trigo e milho não variou e este resultado pode ser reflexo do teor muito alto de fósforo que o solo tinha, por ocasião da implantação das culturas (Comissão de Fertilidade do Solo RS/SC, 1995) (Tabela 2). A quantidade média de fósforo acumulado no milho foi de $22,0 \mathrm{~kg} \mathrm{ha}^{-1}$, enquanto que, para o trigo, de $17,4 \mathrm{~kg}$ $\mathrm{ha}^{-1}$, sendo essa pequena diferença devido à maior concentração no tecido do trigo (média de $0,28 \%$ ) em relação ao milho (média de $0,21 \%$ ). Isso porque quando se considera a produção de matéria seca, observa-se que o milho produziu de 10.000 a $10.925 \mathrm{~kg}$ $\mathrm{ha}^{-1}$, enquanto que o trigo de 5.786 a $6.484 \mathrm{~kg} \mathrm{ha}^{-1}$. Esses resultados reforçam que o trigo é uma cultura mais exigente em fósforo, em relação a outras culturas comerciais, como o milho e soja conforme havia referido PÖTTKER (1999).

O potássio acumulado variou apenas no milho, apesar do seu teor muito alto no solo por ocasião da implantação das culturas (Tabela 2). Contudo, à semelhança do que ocorreu na produção de matéria seca, também no acúmulo de potássio, a distribuição a lanço acabou resultando em menor acúmulo de potássio no tecido do milho, mesmo que, neste caso, o adubo potássico tenha sido aplicado no momento da semeadura do milho (100\% TLa no inverno $+100 \%$ MLa no verão). Estes resultados poderão ser explicados pelo fato do milho ser uma cultura com alta produção de matéria seca e acúmulo de potássio no tecido até o pleno florescimento e a distribuição do potássio a lanço em espaçamento entre linhas de $80 \mathrm{~cm}$, que é o caso, pode ter dificultado sua absorção pelas plantas. Talvez seja por isso que, quando todo o

Tabela 2 - Quantidades de fósforo e potássio acumuladas no tecido do trigo e milho no estádio de pleno florescimento, em função de épocas e formas de aplicação de fósforo e potássio.

\begin{tabular}{|c|c|c|c|c|c|}
\hline \multicolumn{2}{|c|}{ Aplicação do $\mathrm{P}_{2} \mathrm{O}_{5}$ e $\mathrm{K}_{2} \mathrm{O}$} & \multicolumn{4}{|c|}{ Quantidade acumulada no tecido } \\
\hline \multirow{2}{*}{$\begin{array}{l}\text { Trigo } \\
\text { Inverno }\end{array}$} & \multirow{2}{*}{$\begin{array}{l}\text { Milho } \\
\text { Verão }\end{array}$} & \multicolumn{2}{|c|}{ Fósforo } & \multicolumn{2}{|c|}{ Potássio } \\
\hline & & Trigo & Milho & Trigo & Milho \\
\hline \multicolumn{2}{|c|}{ Testemunha } & \multicolumn{4}{|c|}{--o-1 } \\
\hline $100 \% \mathrm{TLi}^{*}$ & $100 \% \mathrm{MLi}$ & $\begin{array}{c}18,9^{\text {ns }} \\
18,7\end{array}$ & $\begin{array}{c}18,8^{\mathrm{is}} \\
23,4\end{array}$ & $\begin{array}{c}120^{15} \\
122\end{array}$ & $\begin{array}{c}189 \mathrm{~b}^{* * *} \\
229 \mathrm{a}\end{array}$ \\
\hline $100 \% \mathrm{TLi}+100 \% \mathrm{MLa}$ & & 17,2 & 21,7 & 131 & $223 \mathrm{a}$ \\
\hline $100 \% \mathrm{TLi}+100 \% \mathrm{MLi}$ & & 18,0 & 23,7 & 123 & $231 \mathrm{a}$ \\
\hline $100 \% \mathrm{TLi}+40 \% \mathrm{MLi}$ & $60 \% \mathrm{MLi}$ & 16,9 & 23,1 & 116 & $232 \mathrm{a}$ \\
\hline $100 \% \mathrm{TLa}+100 \% \mathrm{MLa}$ & & 16,1 & 22,7 & 117 & $225 \mathrm{a}$ \\
\hline $100 \% \mathrm{TLa}+40 \% \mathrm{MLa}$ & $60 \% \mathrm{MLi}$ & 16,1 & 23,4 & 122 & $230 \mathrm{a}$ \\
\hline $100 \% \mathrm{TLa}$ & $100 \% \mathrm{MLa}$ & 17,1 & 18,9 & 128 & $191 \mathrm{~b}$ \\
\hline $100 \% \mathrm{TLa}$ & $100 \% \mathrm{MLi}$ & 17,4 & 22,7 & 118 & $238 \mathrm{a}$ \\
\hline $\mathrm{CV}(\%)$ & & 9,75 & 14,62 & 9,61 & 6,58 \\
\hline
\end{tabular}

* TLi = Adubação recomendada para o trigo aplicada na linha de semeadura. TLa = Adubação recomendada para o trigo aplicada a lanço na semeadura. $\mathrm{MLi}$ = Adubação recomendada para o milho aplicada na linha de semeadura. MLa = Adubação recomendada para o milho aplicada a lanço na semeadura.

** Médias não seguidas de mesma letra na coluna diferem pelo teste Duncan a 5\% de probabilidade de erro.

${ }^{\text {ns }}$ Não significativo. 
potássio do milho foi aplicado na linha de semeadura desta cultura (100\% TLa no inverno $+100 \%$ MLi no verão e também $100 \%$ TLi no inverno $+100 \% \mathrm{MLi}$ no verão), houve maior acúmulo de potássio no tecido, em comparação com o aplicado a lanço na semeadura do milho (100\% TLa no inverno e $100 \%$ MLa no verão). Por outro lado, menor acúmulo de potássio no tecido pode não representar menor produtividade da cultura, pois este nutriente é muito móvel, e através de sua translocação no interior da planta, poderá suprir as exigências de outros órgãos de demanda.

Em anos relativamente secos, a capacidade de absorção de potássio pelas plantas diminui, quando então o efeito da aplicação de potássio poderá ser mais acentuado (HECKMANN \& KAMPRATH, 1992). Contudo, estes mesmos autores mostraram que a aplicação deste nutriente em linha, a lanço ou parte em linha e parte a lanço, mesmo sob várias doses não tem mostrado efeito na acumulação de potássio no tecido do milho, quando o solo possui altos níveis na fração disponível.

A produtividade de grãos de trigo foi em média $13 \%$ superior com a aplicação de fósforo e potássio (Tabela 3). O trigo mostrou ser uma cultura mais sensível à disponibilidade de nutrientes, pois respondeu em produtividade de grãos quando houve a aplicação de fósforo e potássio e é importante observar que não diferiu da testemunha apenas quando os nutrientes foram distribuídos a lanço. No entanto, esse diferencial somente se manifestou após o florescimento da cultura, pois os acúmulos de nutrientes e matéria seca foram semelhantes no pleno florescimento.
A produtividade de grãos de milho foi alta, considerando-se as condições de sequeiro, mas não variou com o uso de fósforo e potássio. No ano agrícola 2002/03, as precipitações foram muito favoráveis ao milho, o que pode justificar a alta produtividade na testemunha, pois a boa disponibilidade de água faz com que os nutrientes disponíveis no solo, principalmente fósforo, se movimentem mais facilmente para a zona de absorção radicular da planta.

A produtividade de grãos das culturas pode não ser afetada mesmo após alguns cultivos, como foi o caso de PÖTTKER (1999). Este autor verificou que não houve variação na produtividade na sucessão trigo/ soja/aveia branca/milho/milho, aplicando fósforo na linha ou a lanço em todos os cultivos, ou intercalando na linha e a lanço em cada cultivo da sucessão. Assim, em anos de baixa disponibilidade de capital, os produtores poderiam até mesmo suprimir a adubação fosfatada, desde que o solo tenha níveis de fósforo acima do nível crítico. Deve-se ressaltar que, além do solo, as características das plantas também podem interferir na resposta à adubação fosfatada e isso ficou demonstrado quando PÖTTKER (1999) trabalhou em solo com teor médio de fósforo e observou que, para o trigo e milho, é preferível a aplicação do fertilizante na linha de semeadura, enquanto que a soja e aveia comportaram-se da mesma forma, quando o fertilizante fosfatado foi aplicado na linha de semeadura ou a lanço, antes da semeadura.

Em solos com baixa capacidade de retenção de fósforo, é possível que a aplicação de fertilizantes fosfatados, juntamente com potássicos, não causem

Tabela 3 - Produtividade de grãos de trigo e milho em função de épocas e formas de aplicação de fósforo e potássio.

\begin{tabular}{|c|c|c|c|}
\hline \multicolumn{2}{|c|}{ Aplicação do $\mathrm{P}_{2} \mathrm{O}_{5}$ e $\mathrm{K}_{2} \mathrm{O}$} & \multicolumn{2}{|c|}{ Produtividade de grãos } \\
\hline Trigo - Inverno & Milho - Verão & Trigo & Milho \\
\hline \multirow{2}{*}{\multicolumn{2}{|c|}{ Testemunha }} & \multicolumn{2}{|c|}{ - $\mathrm{kg} \mathrm{ha}^{-1}$} \\
\hline & & $1.564 \mathrm{~b}^{* *}$ & $9.346^{\mathrm{ns}}$ \\
\hline $100 \% \mathrm{TLi}^{*}$ & $100 \% \mathrm{Mli}$ & $1.816 \mathrm{a}$ & 8.520 \\
\hline $100 \% \mathrm{TLi}+100 \% \mathrm{MLa}$ & & $1.879 \mathrm{a}$ & 8.502 \\
\hline $100 \% \mathrm{TLi}+100 \% \mathrm{MLi}$ & & $1.858 \mathrm{a}$ & 8.909 \\
\hline $100 \% \mathrm{TLi}+40 \% \mathrm{MLi}$ & $60 \% \mathrm{MLi}$ & $1.879 \mathrm{a}$ & 8.939 \\
\hline $100 \% \mathrm{TLa}+100 \% \mathrm{MLa}$ & & $1.823 \mathrm{a}$ & 9.126 \\
\hline $100 \% \mathrm{TLa}+40 \% \mathrm{MLa}$ & $60 \% \mathrm{MLi}$ & $1.681 \mathrm{ab}$ & 8.857 \\
\hline $100 \% \mathrm{TLa}$ & $100 \% \mathrm{MLa}$ & $1.816 \mathrm{a}$ & 8.449 \\
\hline $100 \% \mathrm{TLa}$ & $100 \% \mathrm{MLi}$ & $1.752 \mathrm{ab}$ & 9.018 \\
\hline $\mathrm{CV}(\%)$ & & 6,94 & 5,38 \\
\hline
\end{tabular}

* TLi = Adubação recomendada para o trigo aplicada na linha de semeadura. TLa = Adubação recomendada para o trigo aplicada a lanço na semeadura. $\mathrm{MLi}$ = Adubação recomendada para o milho aplicada na linha de semeadura. MLa = Adubação recomendada para o milho aplicada a lanço na semeadura.

** Médias não seguidas de mesma letra na coluna diferem pelo teste Duncan a 5\% de probabilidade de erro.

${ }^{\text {ns }}$ Não significativo. 
variação na produtividade de grãos de milho, mesmo em solo com teor baixo de fósforo e alto de potássio (MODEL \& ANGHINONI, 1992), pois estes autores aplicaram fósforo e potássio a lanço, em faixas ou na linha de semeadura e obtiveram produtividade média de grãos de $6.880 \mathrm{~kg} \mathrm{ha}^{-1}$, sem haver resposta a aplicação dos fertilizantes.

É possível que, em solos arenosos com alto potássio disponível, possa haver pequeno incremento na produtividade de milho com a aplicação de fertilizante potássico, cuja forma de distribuição na linha, a lanço ou parte na linha e parte a lanço, não altera a produtividade na maioria dos anos (HECKMANN \& KAMPRATH, 1992). Portanto, o solo estando acima do nível crítico, a eficiência das formas de aplicação é semelhante. Por outro lado, é preciso considerar que a aplicação de fertilizantes em superfície pode ter efeitos indesejáveis na qualidade do ambiente, porque aumenta o risco de perdas por escoamento superficial, especialmente em áreas com maiores declividades.

A prática de não adubar uma lavoura, quando os teores de fósforo e potássio estão elevados, poderá ser recomendada para os produtores, mas requer muito cuidado, pois só deverá ser realizada ocasionalmente, com a condição de que o produtor tenha consciência de que seu solo tenderá a baixar os teores de fósforo e potássio disponíveis, à medida que estiver explorando o solo sem a reposição dos nutrientes exportados pelas culturas.

\section{CONCLUSÕES}

Foi evidenciada a baixa probabilidade de resposta em produtividade de grãos à adubação com fósforo e potássio em solo com altos teores destes nutrientes, mostrando que, nestas condições, a aplicação, a lanço ou em linha, na cultura no inverno da adubação que seria utilizada à cultura no verão em sucessão, pode ser justificada pelas facilidades operacionais da adubação em sistemas.

\section{AGRADECIMENTOS}

Ao Engenheiro Agrônomo Aurélio Pavinato e aos técnicos Carlos Alberto Moresco e Vilmar Tusset pelo auxílio na condução do experimento e disponibilização da área experimental da Fazenda Paineira. Especial agradecimento também aos bolsistas de iniciação científica e estudantes de agronomia Isabel Lopes Moreira, Eduardo Girotto, Éder Trentin e Elisandra Pocojeski, pelo auxílio nas análises e discussões sobre o experimento.

\section{REFERÊNCIAS BIBLIOGRÁFICAS}

COMISSÃO DE FERTILIDADE DO SOLO RS/SC (CFS RS/ SC). Recomendações de adubação e calagem para os estados do Rio Grande do Sul e Santa Catarina. SBCS/NRS. 3.ed. Passo Fundo, 1995. 224p.

HECKMANN J.R. Soil Fertility Test Interpretation: Phosphorus, Potassium, Magnesium, and Calcium. Capturado em 22 abr. 2003. Online. Disponível na internet: http// www.rce.Rutgers.edu RUTGERS, The State University of New Jersey. NEW BRUNSWICK, 2003.

HECKMANN, J.R.; KAMPRATH, E.J. Potassium accumulation and corn yield related to potassium fertilizer rate and placement. Soil Science Society of American Journal, Madison, v.56, n.1, p.141-148, jan-fev., 1992.

MODEL, N.S.; ANGHINONI, I. Resposta do milho a modos de aplicação de adubos e técnicas de preparo do solo. Revista Brasileira de Ciência do Solo, Campinas, v.16, n.1, p.55-59, jan-mar, 1992.

PÖTTKER, D.R. Aplicação de fósforo no sistema plantio direto. Passo Fundo : Embrapa Trigo, 1999. 32p. (Boletim de Pesquisa, 2).

SILVEIRA, M.J. Produtividade e análise econômica da utilização de nitrogênio e potássio em milho irrigado por aspersão. 2002. 67f. Dissertação (Mestrado em Agronomia) Programa de Pós-graduação em Agronomia, Universidade Federal de Santa Maria.

TEDESCO, M.J.; VOLKWEISS, S.J.; BOHNEN, H. Análises de solo, plantas e outros materiais. Porto Alegre : UFRGS, Faculdade de Agronomia, 1995. 